\title{
Study of peroral colonic and peritoneal absorption in normal and pathological conditions using a dye
}

\author{
M. SEDKY ABDOU, EMAD S ALEM, GAMALAT MEGAHED, AND M. DANASOURY \\ From Cairo University, U.A.R.
}

EDITORIAL SYNOPSIS The urinary excretion of phenol red was measured over a four-hour period following the administration of a dose of the dye by mouth, by enema, and by intraperitoneal injection. The authors used this as a test of absorption from the small intestine, colon, and peritoneum respectively. Absorption from all three sites was impaired in cirrhotics in proportion to the severity of the liver damage. Intraperitoneal absorption was grossly impaired in local diseases of the peritoneum, and colonic absorption was impaired in colitis.

The most elaborate way of studying absorptionexcretion functions is by the use of radio-isotopes such as radio phosphorus and radio-iron, and ${ }^{131} \mathrm{I}$ labelled tracers such as radio-iodine human serum albumin (RISA) and radioactive triolein and oleic acid (Ruffin, Keever, Chears, Shingleton, Baylin, Isley, and Sanders, 1958; Pimparker, Tulsky, Kalser, and Bockus, 1961; Berkowitz, Croll, and Shapiro, 1962; Moertel, Scudamore, Wollaeger, and Owen, 1962; Rivera, Toro-Goyco, RodriguezMolina, Coca-Mir, and Bernabe-Prida, 1962). Irradiated vitamin $B_{12}$ has been used as well as D-xylose (Santini, Sheehy, and Martinez-de Jesus, 1961), and many dyes, including phenolsulphonphthalein (PSP). The latter has been injected intraperitoneally to test the absorptive function of the peritoneum. Colonic absorption has been tested by means of the colon enema method using radiophosphorus or phenolsulphonphthalein (Matsunaga and Yamaguchi, 1962).

\section{METHOD AND MATERIAL}

We chose phenol red for our intake-excretion tests by the oral route, as a colonic enema, and by intraperitoneal injection because this dye is not an irritant to the body tissues and is promptly and completely excreted in the urine in the amounts absorbed provided that the kidneys are functioning normally.

PERORAL ABSORPTION TEST The patient is given two glasses of water and asked to void urine which is discarded. Then $5 \mathrm{ml}$. of a $0.6 \%$ solution of the dye is added to $250 \mathrm{ml}$. of water and the patient is asked to drink it. Urine is collected throughout the following four hours; the volume is measured accurately and its content of the excreted dye is calculated (Kihara, 1962). This test was carried out on five normal persons and 14 patients, of whom eight were cases of ascites of varying aetiology, and six were cases of cirrhosis of the liver of different types.

PERITONEAL ABSORPTION TEST The method used was that of Matsunaga and Yamaguchi (1962) in which $1 \mathrm{ml}$. of $0.6 \%$ solution of sterile phenol red in $50 \mathrm{ml}$. of Ringer's solution is injected at the midpoint of the MonroRichter line into the peritoneal cavity, with the patient in the dorsal position, and the urine is collected for four hours. This test was performed on five normal persons, on eight cases of ascites of differing aetiology, and on six cases of liver cirrhosis of various origins.

COLONIC ABSORPTION TEST Because of the simplicity of the method, which at the same time gives results comparable with those obtained by radiophosphorus given as an enema, Matsunaga and Yamaguchi (1962) came to the conclusion that it is good enough for the study of colonic absorption and is preferable to the use of radiophosphorus. In this test $2 \mathrm{ml}$. of $0.6 \%$ phenol red dissolved in $250 \mathrm{ml}$. of warm water is injected slowly into the colon while the patient is lying prone with a pillow under the upper part of the thigh so that the pelvis is raised. The patient is kept in this position for 15 minutes after the instillation and then shifted to the left lateral position for another 15 minutes. The urine voided for four hours after the instillation is collected and its volume measured. This test was performed in five normal persons, in eight cases of ascites, in six cases of liver cirrhosis, as well as in five cases of other affections of the colon.

In all these tests, the four-hour collections of urine are tested quantitatively for their content of the excreted dye PSP by changing the sodium phenolsulphonphthalein to the disodium salt by means of $10 \% \mathrm{NaOH}$, avoiding excess of the alkali. The value is adjusted and the red colour compared with a standard dye solution treated similarly, using a photoelectric colorimeter at the wavelength $550 \mathrm{~mm}$. 
In five of the ascites cases and in five more with different liver affections, we measured the intrasplenic tension by the direct percutaneous method and this was taken as an index of the portal venous pressure (Myers and Taylor, 1951 ; Paton, Reynolds, and Sherlock, 1953; Atkinson and Sherlock, 1954).

\section{RESULTS AND DISCUSSION}

By the oral route, the four-hour excretion of the dye varied from $12.4 \%$ to $17.5 \%$ of the ingested amount, with an average of $14.5 \%$. In all the pathological conditions in which this test was performed, there was an impairment of the four-hour excretion but this was least in the cases of ascites due to heart failure, averaging $9.6 \%$, in those of tuberculosis and malignant ascites averaging $8.0 \%$, and in cardiac cirrhosis in which it came down to $7.6 \%$ only. It is noteworthy that the intrasplenic tension was not much raised with only slight impairment of the absorptive function. In cases of bilharzial cirrhosis (fibrosis) with or without ascites, the impaired excretion was much more marked, averaging $3.4 \%$. It is also clear that the impairment in the absorption goes parallel with any increase in the intrasplenic pressure, which is taken as an index of the portal tension. In the one case of Laennec (alcoholic) cirrhosis absorption was also markedly impaired (Tables I and II).

The peritoneal four-hour excretion of the dye varied in the normal subjects from $70 \%$ to $78 \%$ with an average of $74 \%$ of the injected amount, a figure very close to that given by Matsunaga and Yamaguchi (1962) which is $76.4 \%$ in the normal controls. In the cases of ascites, the percentage excretion (an index of absorption) was normal: 77,70 , and $73 \%$ excretion in the cases of peritoneal transudation occurring as a manifestation of congestive heart failure, denoting a normal absorptive function of the peritoneum. In these cases the portal pressure was not much raised, but in bilharzial ascites, with portal hypertension, the peritoneal absorption was impaired to an average of $50.5 \%$ of the injected dye, and, compared with the normal, impaired excretion was down to almost $65 \%$ of the normal excretion. Similarly, dye excretion was impaired in cases of cirrhosis of the liver, whether bilharzial, cardiac, or of Laennec, but more so in bilharzial cases in which the intrasplenic pressure was greatly raised. The most marked impairment in peritoneal absorption was seen in localized peritoneal diseases, down to $18.7 \%$ in the ascitic type of tuberculous peritonitis (a quarter of the normal excretion) and as low as $8 \%$ in malignant ascites occurring in a case of chronic lymphatic leukaemia.

Performing the colonic absorption test on five normal persons the range of the four-hour excretion percentage varied from 6.0 to 11.4 with an average of
TABLE I

PERCENTAGE EXCRETION OF DYE GIVEN BY THREE ROUTES IN NORMALS

\begin{tabular}{|c|c|c|}
\hline Case No. & $\begin{array}{l}\text { Percentage Excretion of } \\
\text { Dye in Four Hours }\end{array}$ & $\begin{array}{l}\text { Route of } \\
\text { Administration }\end{array}$ \\
\hline $\begin{array}{l}1 \\
2 \\
3 \\
4 \\
5\end{array}$ & $\left.\begin{array}{l}12 \cdot 4 \\
13 \cdot 0 \\
17 \cdot 5 \\
13 \cdot 5 \\
16 \cdot 0\end{array}\right\}$ & Oral \\
\hline $\begin{array}{l}1 \\
2 \\
3 \\
4 \\
5\end{array}$ & $\left.\begin{array}{l}70 \\
73 \\
76 \\
73 \\
78\end{array}\right\}$ & Intraperitoneally \\
\hline $\begin{array}{l}1 \\
2 \\
3 \\
4 \\
5\end{array}$ & $\begin{array}{r}8.0 \\
6.0 \\
11.4 \\
8.8 \\
9.6\end{array}$ & Colonic enema \\
\hline
\end{tabular}

TABLE II

PERCENTAGE EXCRETION

\begin{tabular}{|c|c|c|c|c|}
\hline \multirow{2}{*}{$\begin{array}{l}\text { Type of } \\
\text { Disease }\end{array}$} & \multicolumn{3}{|c|}{ Percentage Excretion } & \multirow{2}{*}{$\begin{array}{l}\text { Intrasplenic } \\
\text { Pressure } \\
\left(\mathrm{cm} . \mathrm{H}_{2} \mathrm{O}\right)\end{array}$} \\
\hline & Oral & Peritoneal & Colon & \\
\hline Bilharzial & $\begin{array}{l}4 \cdot 7 \\
4 \cdot 6 \\
3 \cdot 2\end{array}$ & $\begin{array}{l}52 \cdot 8 \\
50 \cdot 8 \\
48 \cdot 0\end{array}$ & $\begin{array}{l}4 \cdot 5 \\
4.9 \\
5 \cdot 0\end{array}$ & $\begin{array}{l}75 \\
72 \\
65\end{array}$ \\
\hline Tuberculosis & $8 \cdot 0$ & $18 \cdot 0$ & $8 \cdot 1$ & \\
\hline Congestion & $\mathbf{7 \cdot 7}$ & 77 & $7 \cdot 5$ & 50 \\
\hline Heart failure & $11 \cdot 0$ & 70 & $7 \cdot 3$ & 47 \\
\hline Malignant & $8 \cdot 0$ & $8 \cdot 0$ & $7 \cdot 0$ & \\
\hline \multirow[t]{3}{*}{ Bilharzial } & $4 \cdot 3$ & 54 & $4 \cdot 0$ & 70 \\
\hline & $2 \cdot 5$ & 55 & $4 \cdot 2$ & 73 \\
\hline & $1 \cdot 4$ & $54 \cdot 3$ & $3 \cdot \overline{8}$ & 75 \\
\hline Laennec & $3 \cdot 0$ & 48 & $4 \cdot 5$ & \\
\hline \multirow[t]{2}{*}{ Cardiac } & $7 \cdot 0$ & 60 & $5 \cdot 0$ & 55 \\
\hline & $8 \cdot 2$ & 58 & $5 \cdot 2$ & 52 \\
\hline \multicolumn{2}{|c|}{ Chronic colitis } & & 6.0 & \\
\hline \multirow{2}{*}{\multicolumn{2}{|c|}{$\begin{array}{l}\text { Chronic colitis } \\
\text { Ulcerative colitis }\end{array}$}} & & $3 \cdot 0$ & \\
\hline & & & $5 \cdot 4$ & \\
\hline \multicolumn{2}{|c|}{ Ulcerative colitis } & & 3.0 & \\
\hline \multicolumn{2}{|c|}{ Regional ileitis } & & $5 \cdot 0$ & \\
\hline
\end{tabular}

almost 9.0. In peritoneal affections (ascites), the excretion was within the range of the normal in congestive heart failure and nearly so in tuberculous and malignant ascites. In all the cases of cirrhosis of the liver, the colonic absorption was impaired, more so in the bilharzial cases with an average of $4.4 \%$, i.e., less than half the normal function. This occurred in the cases of bilharzial fibrosis with or without ascites but all having the common feature of a raised intrasplenic pressure ranging from 65 to $75 \mathrm{~cm}$. of water, paralleling a similar rise in the portal tension, of which it is taken as an index. In five cases of colonic disease, comprising two cases of chronic non-specific colitis, two cases of ulcerative colitis, and one case of regional ileitis, the colon absorption test was performed and showed a variable degree of impaired absorptive function. 
From the above data, if we take the peroral absorption of the dye as denoting primarily the absorptive function of the small intestine and the large bowel to a lesser extent, we can deduce that these are pathological in bilharzial as well as in Laennec's cirrhosis. And there is good correlation between the rise in the portal tension, which can be taken as denoting the degree of the cirrhosis, and the impairment in absorptive function (Ralli, Robson, Clarke, and Hoagland, 1945).

The intraperitoneal injection of dye has shown that the peritoneum is a very efficient absorptive membrane when compared with the intestinal mucosa; coming far behind is the mucosal surface of the small gut; and last is the colonic mucosa. Comparing the results obtained in the different pathological conditions, we can deduce that the peritoneum is affected, like the intestines, in cases of cirrhosis of the liver, bilharzial and Laennec's, and even to some extent in cardiac cirrhosis. The extent of the impairment in absorptive function in these cases is parallel to the rise in the portal tension. In the case of ascitic transudation in heart failure, peritoneal absorptive function is not impaired but in cases of cardiac cirrhosis, with almost the same reading for the portal tension, there is diminution of function, indicating that this is a reflection in the peritoneum of the liver affection. Lastly, when there is localized peritoneal disease, the impairment is very marked, as in the cases of tuberculous peritonitis and the malignant infiltration in lymphatic leukaemia.

Similar deductions are applicable to the colon enema absorption test which has shown a functional impairment in absorption in cases of liver cirrhosis as well as in localized diseases of the colon.

\section{SUMMARY AND CONCLUSIONS}

The intake-excretion test was performed using a dye, phenol red, by the oral, peritoneal, and colonic instillation routes. The tests were performed on 15 normal subjects, of whom five were selected for each of the three routes. For four hours after the intake of the dye by any of the three different routes, the urine was collected and its content of the excreted dye was calculated by comparing with a standard solution of the dye using a photocolorimeter. Kidney function tests were performed to avoid any abnormality in the excretory functions of the kidneys interfering with the results.

The same tests were done in eight cases of ascites (three bilharzial, three due to congestive heart failure, one of tuberculous peritonitis, and one infiltration in chronic lymphatic leukaemia) and in six cases of cirrhosis of the liver of which three were bilharzial, two cardiac, and one portal Laennec.
In the bilharzial ascites cases as well as in all the cases of cirrhosis, many liver function tests were done to gauge the degree of liver damage. In 10 of the patients, the percutaneous intrasplenic tension was measured and the readings were taken as an index of the portal venous pressure. In addition, the colon enema test was performed on five further patients with localized diseases of the colon.

We can conclude from our data that the normal excretion in the three tests has been standardized. Peritoneal and colonic absorption was found to be impaired in localized disease. The intraperitoneal test may thus be helpful in the diagnosis of local peritoneal affections, in detecting such affections early before frank signs, such as ascites, appear, as well as in the differential diagnosis of certain cases of the latter conditions. The peritoneal, colonic, and intestinal absorption is impaired in all types of cirrhosis of the liver but more so in the bilharzial and portal than in the cardiac, denoting a secondary affection of the absorptive surfaces of the peritoneum and the small and large gut in liver disease. In cases of cirrhosis of the liver, impaired absorption correlates well with the rise in portal tension which, in turn, is an index of the degree of liver affection.

\section{REFERENCES}

Atkinson, M., and Sherlock, S. (1954). Intrasplenic pressure as an index of portal venous pressure. Lancet, 1, 1325-1327.

Berkowitz, D., Croll, N. M., and Shapiro, B. (1962). Evaluation of radioisotopic triolein techniques in the detection of steatorrhea. Gastroenterology, 42, 572-579.

Janssen, B., Jr., Tyor, M. P., Owen, E. E., and Ruffin, J. M. (1960). Absorption of $\mathrm{I}^{131}$ labelled lipids after intraduodenal administration: effect of lipid prefeeding. Ibid., 38, 211-216.

Kihara, T. (1962). Absorption function of the small intestine in liver diseases. Jap. J. Gastroent., Proc., 2, 39.

Matsunaga, P., and Yamaguchi, T. (1962). Studies on colonic and peritoneal absorption. Ibid., Proc., 2, 14.

Moertel, C. G., Scudamore, H. H., Wollaeger, E. E., and Owen, C. A., Jr. (1962). Limitations of the $I^{131}$-labelled triolein tests in the diagnosis of steatorrhea. Gastroenterology, 42, 16-21.

Myers, J. P., and Taylor, W. J. (1951). An estimation of portal venous pressure by occlusive catheterization of an hepatic venule. J. clin. Invest., 30, 662-663.

Paton, A., Reynolds, T. B., and Sherlock S. (1953). Assessment of portal venous hypertension by catheterisation of hepatic vein. Lancet, 1, 918-921.

Pimparkar, B. D., Tulsky, E. G., Kalser, M. H., and Bockus, H L. (1961). Correlation of radioactive and chemical fecal fat determinations in the malabsorption syndrome. I. Studies in normal man and in funstional disorders of the gastrointestinal tract. Amer. J. Med., 30, 910-926.

Ralli, E. P., Robson, J. S., Clarke, D., and Hoagland, C. L. (1945). Factors influencing ascites in patients with cirrhosis of the liver. J. clin. Invest., 24, 316-325.

Rivera, J. V., Toro-Goyco, E., Rodriguez-Molina, R., Coca-Mir, R., and Bernabe-Prida, R. (1962). The triolein absorption test in the diagnosis of stetorrhea. Gastroenterology, 43, 13-23.

Ruffin, J. M., Keever, I. C., Chears, C., Jr., Shingleton, W. W., Baylin, G. J., Isley, J. K., and Sanders, A. P. (1958). Further observations on the use of $I^{131}$-labeled lipids in the study of diseases of the gastrointestinal tract. Ibid., 34, 484-490.

Santini, R. Jr., Sheehy, T. W., and Martinez-de Jesus, J. (1961). The xylose tolerance test with a five-gram dose. Ibid., 40,
772-774. 